\title{
QUANTUM CHEMICAL MODELING OF UV SPECTRA OF POLYURETHANE STRUCTURAL FRAGMENTS
}

\author{
M. A. Ksenofontov, ${ }^{a}$ D. S. Umreiko, ${ }^{a}$ and M. B. Shundalau ${ }^{b *}$
}

UDC 539.19:678.664

Results of TDDFT calculations of characteristics for excited singlet states of mono- and diisocyanates and carbamates containing from one to three phenyl groups are presented. The influence of the structural composition of the isocyanate/carbamate on the formation of its UV absorption spectrum was analyzed.

Keywords: ab initio calculation, density functional theory, UV spectrum, isocyanates, urethanes.

Introduction. Polyurethanes represent a modern multifaceted class of polymers with a broad range of applications in various industrial sectors owing to their ability to form macromolecular structures of defined architectures [1]. Linear segmented urethane polymers that were synthesized via the reaction of hydroxyl-containing derivatives with isocyanates included flexible and rigid segments in their structures. As a rule, the flexible segments consisted of ethers or esters and imparted to the polyurethane a high level of elasticity. The structures of the rigid short-chain segments were determined by the structures of the starting di- and polyisocyanates [2].

Experimental methods such as vibrational spectroscopy that are supplemented by results of quantum-chemical calculations are often used in research on the structural and physical properties of urethane polymers incorporating isolated functional groups in their compositions and also starting compounds for polyurethane synthesis [3-8]. Previously performed $a b$ initio and DFT calculations of the structural, spectral, and energy characteristics of several urethane representatives, e.g., methylcarbamate (MC) [9], methylphenylcarbamate (MPC) [10], 4,4'-diphenylmethane-bis(methyl)carbamate (DPMC) [11], and a representative of the diisocyanate family and one of the polyurethanes used most frequently in industry, 4,4'-diphenylmethanediisocyanate (MDI) [12], demonstrated that the examined structural models of the polyurethane chain fragments were adequate. Nevertheless, these calculations exposed the limitations of vibrational spectroscopy methods for analyzing the structural features of the polyurethane chain because notable trends in the calculated spectra of three examined urethanes were not observed other than a tendency of the frequency of the $\mathrm{C}=\mathrm{O}$ stretching vibration to decrease in the order MC $\rightarrow$ MPC $\rightarrow$ DPMC [11]. An analogous situation was typical of the vibrational spectra of phenylisocyanate (PI) and MDI [12].

Polymers containing carboxyl chromophores or amino or phenyl groups are known to absorb significantly in the UV region. However, as a rule, vibronic spectra of such polymers are unimpressive and rarely used to study their structures [13]. Nevertheless, an analysis of UV absorption bands (ABs) of polymers enables certain conclusions to be made about the number of units or functional groups in the polymer chain because the $A B$ shifts systematically to long wavelength as the chain lengthens because the frontier molecular orbitals approach each other [13]. Time-dependent or non-stationary density functional theory (TDDFT) is currently widely used to model electronic spectra of polyatomic systems [14-20]. It was noted that a typical quantum-chemical calculation performed using the hybrid functional B3LYP in terms of the TDDFT approximation displays deviations of the excited state energies from the experimental values of the order of $0.4 \mathrm{eV}$ [15]. This enables results of TDDFT calculations to be used for predictions and analysis.

Herein we present results of TDDFT quantum-chemical calculations of several characteristics of the excited electronic states of two isocyanates, PI OCN- $\mathrm{C}_{6} \mathrm{H}_{5}$ (I) and MDI OCN-C $6 \mathrm{H}_{4}-\mathrm{CH}_{2}-\mathrm{C}_{6} \mathrm{H}_{4}-\mathrm{NCO}$ (II), in addition to four urethanes, MC $\mathrm{CH}_{3}-\mathrm{OC}(\mathrm{O}) \mathrm{NH}_{2}$ (III), MPC $\mathrm{CH}_{3}-\mathrm{OC}(\mathrm{O}) \mathrm{NH}-\mathrm{C}_{6} \mathrm{H}_{5}$ (IV), DPMC $\mathrm{CH}_{3}-\mathrm{OC}(\mathrm{O}) \mathrm{NH}-\mathrm{C}_{6} \mathrm{H}_{4}-\mathrm{CH}_{2}-\mathrm{C}_{6} \mathrm{H}_{4}-$

\footnotetext{
*To whom correspondence should be addressed.
}

${ }^{\mathrm{a}}$ A. N. Sevchenko Institute of Applied Physical Problems, Belarusian State University, Minsk; e-mail: lab_ dozator@mail.ru; belarusian State University, 4 Nezavisimost' Ave., Minsk, 220030, Belarus; e-mail: shundalov @bsu.by. Translated from Zhurnal Prikladnoi Spektroskopii, Vol. 79, No. 3, pp. 361-365, May-June, 2012. Original article submitted August 24, 2011. 


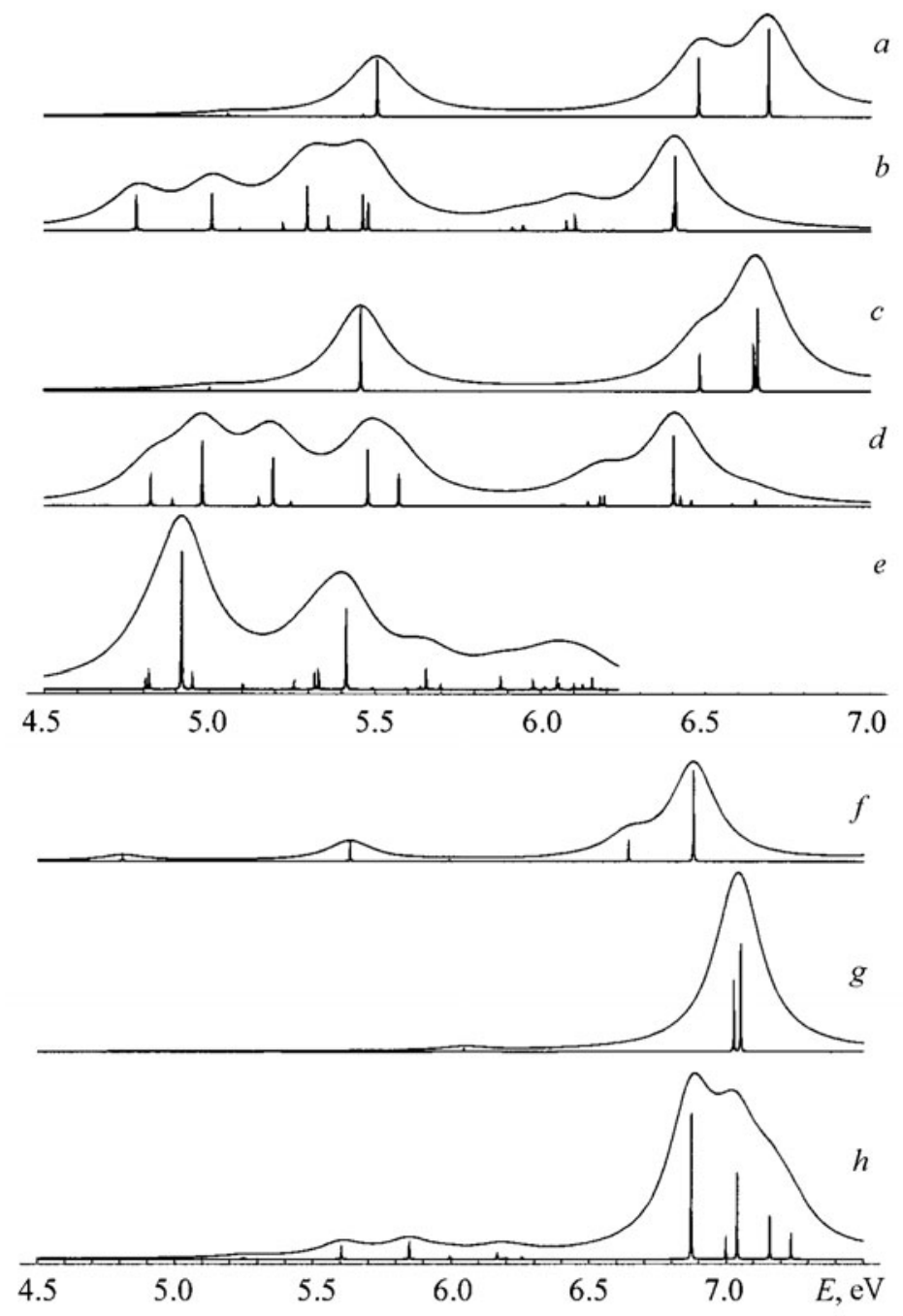

Fig. 1. Model electronic absorption spectra of I (a), II (b), IV (c), V (d), VI (e), VII (f), VIII (g), and IX (h).

$\mathrm{HN}(\mathrm{O}) \mathrm{CO}-\mathrm{CH}_{3}(\mathbf{V})$, and a model dicarbamate VI, the structure of which was based on the DPMC chain with the incorporation into the central part of the molecule of a single phenyl and a single methyl: $\mathrm{CH}_{3}-\mathrm{OC}(\mathrm{O}) \mathrm{NH}-\mathrm{C}_{6} \mathrm{H}_{4}-\mathrm{CH}_{2}-$ $\mathrm{C}_{6} \mathrm{H}_{4}-\mathrm{CH}_{2}-\mathrm{C}_{6} \mathrm{H}_{4}-\mathrm{HN}(\mathrm{O}) \mathrm{CO}-\mathrm{CH}_{3}$. These urethanes include the principal functional groups found in a typical polyurethane (urethane, phenyl, methyl, and methylene) and can act as models of polymer structural fragments.

Calculation Procedure. Spectral characteristics of the examined compounds were calculated using the applied quantum-chemical program GAMESS [21, 22]. The results were visualized using the program MacMolPlt [23]. All calculations were performed in the standard basis set cc-pVDZ [24] using TDDFT methods and the hybrid exchangecorrelated functional B3LYP [25-27]. The equilibrium configurations of I-IV that were found earlier [9, 10, 12] were used to model their absorption spectra. Full geometry optimization in the B3LYP/cc-pVDZ approximation based on the equilibrium structure of DMPC obtained earlier in the HF/6-311G approximation [11] was carried out for $\mathbf{V}$ and VI.

Results and Discussion. Energy characteristics of 20 excited singlet electronic states were calculated for each of I-V; 30 states, for VI. Table 1 presents the results from calculations for the 20 lowest states. Figure 1 shows model spectra of $\mathbf{I}, \mathbf{I I}, \mathbf{I V}$, and $\mathbf{V}$ at excitation energies up to $7 \mathrm{eV}$ and of $\mathbf{V I}$ at excitation energies up to $6.3 \mathrm{eV}$. Systems of energy states of aniline $\mathrm{C}_{6} \mathrm{H}_{5}-\mathrm{NH}_{2}$ (VII), toluene $\mathrm{C}_{6} \mathrm{H}_{5}-\mathrm{CH}_{3}$ (VIII), and diphenylmethane $\mathrm{C}_{6} \mathrm{H}_{5}-\mathrm{CH}_{2}-\mathrm{C}_{6} \mathrm{H}_{5}$ (IX) were also calculated in order to assign more completely the $\mathrm{ABs}$ to chromophores. Figure 1 shows model spectra of these compounds at excitation energies up to $7.5 \mathrm{eV}$. 
TABLE 1. Energies of Lower Excited Singlets of Electron States, Wavelengths, and Transition Oscillator Strengths from the Ground State

\begin{tabular}{|c|c|c|c|c|c|c|c|c|c|c|c|c|c|c|c|c|c|}
\hline \multicolumn{3}{|c|}{ I } & \multicolumn{3}{|c|}{ II } & \multicolumn{3}{|c|}{ III } & \multicolumn{3}{|c|}{ IV } & \multicolumn{3}{|c|}{$\mathbf{V}$} & \multicolumn{3}{|c|}{ VI } \\
\hline$E, \mathrm{eV}$ & $\lambda, \mathrm{nm}$ & $S$ & $E, \mathrm{eV}$ & $\lambda, \mathrm{nm}$ & $S$ & $E, \mathrm{eV}$ & $\lambda, \mathrm{nm}$ & $S$ & $E, \mathrm{eV}$ & $\lambda, \mathrm{nm}$ & $S$ & $E, \mathrm{eV}$ & $\lambda, \mathrm{nm}$ & $S$ & $E, \mathrm{eV}$ & $\lambda, \mathrm{nm}$ & $S$ \\
\hline 5.06 & 245 & 0.012 & 4.78 & 259 & 0.158 & 6.85 & 181 & 0 & .00 & 248 & 0.014 & 4.82 & 257 & 0.125 & 4.81 & 258 & 0.040 \\
\hline 5.46 & 227 & 0.007 & 4.95 & 251 & 0.003 & 7.55 & 164 & 0.007 & 5.46 & 227 & 0.366 & 4.89 & 254 & 0.028 & 4.82 & 257 & 0.069 \\
\hline 5.51 & 225 & 0.250 & 5.01 & 248 & 0.166 & 7.93 & 156 & 0.034 & 6.20 & 200 & 0 & 4.98 & 249 & 0.286 & 4.92 & 252 & 0.602 \\
\hline 6.43 & 193 & 0 & 5.09 & 243 & 0.012 & 8.35 & 149 & 0.040 & 6.43 & 193 & 0 & 5.15 & 241 & 0.041 & 4.95 & 250 & $\mid 0.074$ \\
\hline 6.48 & 191 & 0.263 & 5.22 & 237 & 0.031 & 8.50 & 146 & 0.072 & 6.48 & 191 & 0.167 & 5.19 & 239 & 0.215 & 5.03 & 247 & 0.002 \\
\hline 6.58 & 188 & 0.002 & 5.30 & 234 & 0.198 & 8.66 & 143 & 0.149 & 6.64 & 187 & 0.187 & 5.25 & 236 & 0.019 & 5.10 & 243 & 0.022 \\
\hline 6.69 & 185 & 0.389 & 5.35 & 232 & 0.002 & 8.80 & 141 & 0.031 & 6.67 & 186 & 0.361 & 5.48 & 226 & 0.251 & 5.26 & 236 & 0.033 \\
\hline 6.96 & 178 & 0 & 5.36 & 231 & 0.068 & 8.88 & 140 & 0.011 & 7.01 & 177 & 0.001 & 5.57 & 223 & 0.143 & 5.32 & 233 & $\mid 0.068$ \\
\hline 7.20 & 172 & 0 & 5.46 & 227 & 0.162 & 8.98 & 138 & 0.024 & 7.15 & 173 & 0.054 & 6.06 & 205 & 0.006 & 5.33 & 232 & 0.069 \\
\hline 7.46 & 166 & 0.352 & 5.48 & 226 & 0.125 & 9.11 & 136 & 0.026 & 7.38 & 168 & 0.001 & 6.07 & 204 & 0.006 & 5.35 & 231 & 0.007 \\
\hline 7.49 & 165 & 0.007 & 5.91 & 210 & 0.018 & 9.43 & 132 & 0.052 & 7.42 & 167 & 0.015 & 6.14 & 202 & 0.022 & 5.41 & 230 & 0.354 \\
\hline 7.78 & 160 & 0.107 & 5.95 & 209 & 0.025 & 9.68 & 128 & 0.015 & 7.46 & 166 & 0.002 & 6.18 & 201 & 0.047 & 5.50 & 226 & 0.006 \\
\hline 7.80 & 159 & 0.001 & 6.08 & 204 & 0.046 & 9.86 & 126 & 0.013 & 7.49 & 166 & 0.029 & 6.19 & 200 & 0.047 & 5.60 & 222 & 0.004 \\
\hline 7.86 & 158 & 0 & 6.10 & 203 & 0.056 & 9.87 & 126 & 0.006 & 7.61 & 163 & 0.019 & 6.22 & 199 & 0.001 & 5.64 & 220 & $\mid 0.013$ \\
\hline 7.88 & 157 & 0 & 6.19 & 200 & 0.002 & 10.03 & 124 & 0.021 & 7.70 & 161 & 0 & 31 & 196 & 0.002 & 5.66 & 219 & 0.087 \\
\hline 7.98 & 155 & 0 & 6.22 & 199 & 0.002 & 10.19 & 122 & 0.008 & 7.88 & 158 & 0.003 & 6.40 & 194 & 0.310 & 5.70 & 218 & 0.017 \\
\hline 8.05 & 154 & 0.004 & 6.40 & 194 & 0.069 & 10.20 & 122 & 0.003 & 7.92 & 157 & 0.001 & 6.42 & 193 & 0.044 & 5.80 & 214 & 0 \\
\hline 8.18 & 152 & 0.001 & 6.41 & 194 & 0.330 & 10.22 & 121 & 0.016 & 7.98 & 156 & 0.006 & 6.46 & 192 & 0.024 & 5.88 & 211 & 0.058 \\
\hline 8.32 & 149 & 0.002 & 6.43 & 193 & 0 & 10.24 & 121 & 0.016 & 8.00 & 155 & 0.035 & 6.58 & 188 & 0.010 & 5.98 & 207 & 0.035 \\
\hline 8.40 & 148 & 0.002 & 6.44 & 193 & 0 & 10.31 & 120 & 0.059 & 8.01 & 155 & 0.019 & 6.65 & 186 & 0.032 & 5.98 & 207 & 0 \\
\hline \multicolumn{18}{|c|}{$\Delta E_{\mathrm{H}-\mathrm{L}}, \mathrm{eV}$} \\
\hline & 5.74 & & & 5.33 & & & 8.54 & & & 5.82 & & & 5.4 & & & 5.36 & \\
\hline
\end{tabular}

Let us first analyze model electronic spectra of compounds containing only one phenyl (I and IV), noting that their structures are exceedingly complicated (Fig. 1a and c). ABs were observed at 275, 230, and $222 \mathrm{~nm}$ in the experimental vibronic spectrum of PI in the range 300-200 nm [28]. The first of these (much weaker) demonstrated clearly resolved vibrational structure analogous to the vibronic transition in the spectrum of benzene at $\sim 260 \mathrm{~nm}$ [29]. Thus, the weak $\mathrm{AB}$ at $245 \mathrm{~nm}(5.06 \mathrm{eV})$ in the spectrum of I; 248 (5.01) (IV), 258 (4.81) (VII), and 232 (5.34) (VIII) corresponded to the forbidden transition ${ }^{1} A_{1 g} \rightarrow{ }^{1} B_{2 u}(256 \mathrm{~nm})$ in the spectrum of benzene [30]. Bands at 193 and $185 \mathrm{~nm}(6.43$ and $6.69 \mathrm{eV})$ in the spectrum of $\mathbf{I}$; at 193 and 187 (6.43 and 6.64) in that of $\mathbf{I V}$; at 191 and 180 (6.49 and 6.89) in that of VII; and at 205 and 175 (6.05 and 7.09) in the spectrum of VIII corresponded with the two other electronic transitions of benzene that fell in the UV region below $170 \mathrm{~nm}$ \{also forbidden ${ }^{1} A_{1 g} \rightarrow{ }^{1} B_{1 u}$ (203 $\mathrm{nm})$ and allowed ${ }^{1} A_{1 g} \rightarrow{ }^{1} E_{1 u}$ (180) [30]\}.

Two transitions in the range 200-230 nm (6.20-5.39 eV), one of which (longer wavelength in spectra of IV and VII) was rather strong; the other, close to zero, corresponded to absorption of the aniline amine (VII), the MPC $\mathrm{NH}$ (IV), and the PI $-\mathrm{N}=\mathrm{C}=\mathrm{N}$-containing fragment (I). Toluene (VIII) did not absorb in this range in the calculated spectrum. It is noteworthy that the calculation in general reproduced adequately the system of PI lower singlet states. The energy of the first excited state was elevated by $0.55 \mathrm{eV}$; of the second, by 0.07 ; of the third, lowered by 0.08 .

Absorption of the $\mathrm{C}=\mathrm{O}$ chromophore [30] in spectra of $\mathbf{I}$ and $\mathbf{I V}$ corresponded to a strong $\mathrm{AB}$ at $191 \mathrm{~nm}$ $(6.48 \mathrm{eV})$. Absorption of the methyl was seen as strong ABs at 186 and $176 \mathrm{~nm}(6.67$ and $7.05 \mathrm{eV})$ in spectra of IV 
and VIII. It should be mentioned that such assignments were somewhat arbitrary because up to 30 pairs of molecular orbitals contributed to these transitions as a result of strong intramolecular interaction.

Electronic spectra of compounds incorporating into their structures two benzene rings and a methylene group (IX) in addition to two isocyanates (II) or urethanes (V) exhibited complicated structures (Fig. 1b and d). The most characteristic difference of the spectra of these compounds and those examined above was a significant bathochromic shift of the ABs. Furthermore, the symmetry of the molecular fragments was reduced (this refers mainly to the benzene rings) together with an overall increase in the number of chromophores, which increased the number of ABs. In turn, this was accompanied by a strengthening of previously forbidden transitions. An example was the two strong transitions in the range $260-240 \mathrm{~nm}(4.77-5.17 \mathrm{eV})$ in spectra of II and $\mathbf{V}$ that were analogs of the aforementioned ${ }^{1} A_{1 g} \rightarrow{ }^{1} B_{2 u}$ transition in the spectrum of benzene. Weak ABs due to the presence of a methylene group in the structures of II, $\mathbf{V}$, and $\mathbf{I X}$ also appeared in this range. The features mentioned above (bathochromic shift and strengthening of $\mathrm{ABs}$ ) were not observed in the spectrum of diphenylmethane (IX). This enabled them to be explained mainly as a manifestation of intramolecular interaction (inductive effect). The short-wavelength spectral range 200-175 nm (6.20-7.09 eV) also underwent substantial changes. Only one of two strong ABs remained at $194 \mathrm{~nm}(6.29 \mathrm{eV})$. It was due primarily to absorption of the carbonyl chromophore (Fig. 1a-d).

Adding additional moieties (benzene and methylene groups) to the DMPC structure did not cause a significant bathochromic shift of the $\mathrm{ABs}$ in the spectrum of $\mathbf{V I}$ relative to the position of the ABs in the spectrum of $\mathbf{V}$ (Table 1). Nevertheless, such a structural change was accompanied by a redistribution of intensity in the long-wavelength region because the transition at $252 \mathrm{~nm}(4.92 \mathrm{eV})$ due to absorption of the central benzene ring that was missing in the structures of II and IV dominated.

The spectrum of the simplest urethane III differed in principle from those of the other urethanes and isocyanates because it was determined by absorption of amine and urethane chromophores. The ABs in the spectrum of III experienced a significant hypsochromic shift relative to that in spectra of IV and $\mathbf{V}$. Thus, the carbonyl absorption appeared at $146 \mathrm{~nm}(8.50 \mathrm{eV})$; amine, $143(8.66)$. The energy differences of the highest occupied and lowest unoccupied molecular orbitals $\Delta E_{\mathrm{H}-\mathrm{L}}$ (Table 1) in the series I $\rightarrow$ II and III $\rightarrow$ IV $\rightarrow \mathbf{V} \rightarrow$ VI demonstrated a smooth decrease caused by the increasing number of functional groups in their structures.

Conclusion. Changes of electronic absorption spectra that were due to different numbers of functional groups

in the structures of isocyanate or urethane chains were analyzed using quantum-chemical TDDFT modeling of electronic structures of isocyanates and carbamates containing one or two isocyanate or urethane groups in addition to one to three benzene rings. It was shown that the position of the ABs in the electronic spectrum was determined mainly by the number of structural elements (phenyl and urethane/isocyanate groups) incorporated into the carbamate/isocyanate. The influence of the terminal functional groups (urethane or isocyanate) on the formation of the electronic spectrum structure seemed less significant. The established features could be used for analytical purposes.

\section{REFERENCES}

1. G. Oertel, Polyurethane Handbook, Hanser Publishers, New York (1985).

2. I. Krakovsky, J. Plestil, J. Baldrian, and M. Wubbenhorst, Polymer, 43, 4989-4996 (2002).

3. J. Bandekar and S. Klima, J. Mol. Struct., 263, 45-57 (1991).

4. T. V. Kozlova, S. V. Vdovina, and V. V. Zharkov, Vysokomol. Soedin., Ser. A, 33, 831-836 (1991).

5. S. L. Huang and J.-Y. Lai, Eur. Polym. J., 33, 1563-1567 (1997).

6. J. Bandekar and S. Klima, Spectrochim. Acta, Part A, 48, 1363-1370 (1992).

7. J. Bandekar and Y. Okuzumi, J. Mol. Struct.: THEOCHEM, 281, 113-122 (1993).

8. E. Yoilgor, I. Yoilgor, and E. Yurtsever, Polymer, 43, 6551-6559 (2002).

9. M. B. Shundalov, G. A. Pitsevich, M. A. Ksenofontov, and D. S. Umreiko, Zh. Prikl. Spektrosk., 76, No. 3, 349-357 (2009).

10. M. B. Shundalov, G. A. Pitsevich, M. A. Ksenofontov, and D. S. Umreiko, Zh. Prikl. Spektrosk., 76, No. 4, 485-492 (2009).

11. M. B. Shundalov, G. A. Pitsevich, M. A. Ksenofontov, and D. S. Umreiko, Zh. Prikl. Spektrosk., 77, No. 3, 333-339 (2010). 
12. G. A. Pitsevich, M. B. Shundalau, M. A. Ksenofontov, and D. S. Umreiko, Global J. Anal. Chem., 2, 114-124 (2011).

13. Encyclopedia of Polymers, Vol. 3, Sov. Éntsiklopediya, Moscow (1977).

14. C. Adamo and V. Barone, Chem. Phys. Lett., 330, 152-160 (2000).

15. K. Burke, J. Werschnik, and E. K. U. Gross, J. Chem. Phys., 123, 062206 (2005).

16. G. F. Zhao, Y. Lei, and Z. Zeng, Chem. Phys., 327, 261-268 (2006).

17. L. Miao, Y. Yao, F. Yang, Z. Wang, W. Li, and J. Hu, J. Mol. Struct.: THEOCHEM, 865, $79-87$ (2008).

18. M. E. Casida, J. Mol. Struct.: THEOCHEM, 914, 3-18 (2009).

19. J. Fabian, Dyes Pigm., 84, 36-53 (2010).

20. M. Belletete, P.-L. T. Boudreault, M. Leclerc, and G. Durocher, J. Mol. Struct.: THEOCHEM, 962, 33-37 (2010).

21. M. W. Schmidt, K. K. Baldridge, J. A. Boatz, S. T. Elbert, M. S. Gordon, J. H. Jensen, S. Koseki, N. Matsunaga, K. A. Nguyen, S. J. Su, T. L. Windus, M. Dupuis, and J. A. Montgomery, J. Comput. Chem., 14, 13471363 (1993).

22. http://www.msg.ameslab.gov/GAMESS/GAMESS.html

23. B. M. Bode and M. S. Gordon, J. Mol. Graphics Model., 16, 133-138 (1998).

24. T. H. Dunning, Jr., J. Chem. Phys., 90, 1007-1023 (1998).

25. A. D. Becke, J. Chem. Phys., 98, 5648-5652 (1993).

26. C. Lee, W. Yang, and R. G. Parr, Phys. Rev. B: Condens. Matter Mater. Phys., 37, 785-789 (1988).

27. P. J. Stephens, F. J. Devlin, C. F. Chabalowski, and M. J. Frisch, J. Phys. Chem., 98, 11623-11627 (1994).

28. W. J. Balfour, T. W. Dingle, and R. S. Ram, J. Mol. Spectrosc., 96, 306-312 (1982).

29. G. Herzberg, Electronic Spectra and Electronic Structure of Polyatomic Molecules, Van Nostrand, New York (1966).

30. O. V. Sverdlova, Electronic Spectra in Organic Chemistry [in Russian], Khimiya, Leningrad (1985). 